\title{
Study on the Reasons Why Chengdu Qingyang Temple Industrial Exposition Was Reorganized in the Period of Republic of China (1920-1928)
}

\author{
Fei Zhao ${ }^{1, a}$ \\ ${ }^{1}$ School of History and Culture, Sichuan University, Chengdu, Sichuan Province, China \\ a1029968560@qq.com
}

Keywords: Qingyang Temple; Industrial Association; Industrial; Local Autonomy; Chengdu.

\begin{abstract}
In 1920, Sichuan authorities reorganized Industrial Exposition in Qingyang Temple, which was the first time to hold this Industrial Exposition since the Revolution of 1911 nearly a decade of stagnation. The reasons included mainly: authorities had changed attitude toward the temple and advocated to develop industries, as well as the consideration of local autonomy and the development of domestic products in politics. Keeping the whole country in view, Sichuan had gone ahead in China, but unfortunately, because of the remote location of southwestern of China, people in other province have not noticed Qingyang Temple Industrial Exposition.
\end{abstract}

\section{Introduction}

Qingyang Temple and Erxian Taoist Temple, which were located three or four miles southwest of Chengdu, were the biggest Taoist Temple in Chengdu. As we all know, Qingyang Temple was famous for Flower Show, which has been going on since the ancient country of Shu. And the Flower Show were run by nongovernmental organization and the popular. Until the end of the Qing Dynasty, Sichuan industrial bureau changed Flower Show to Commerce and Industrial Exposition, since then the authorities started to manage this activity, instead of nongovernmental organization and the popular. Stepped in the Republican of China, authorities had gave up the management of Commerce and Industrial Exposition because of economic and political reasons, so Commerce and Industrial Exposition returned to Flower Show. Until the year of 1920, authorities reorganized this activity, and changed the name to Industrial Exposition. Why authorities reorganized? Why was it happened in 1920 ? Behind the activity, which factors were involved in? All of the questions are the focus of this paper.

In the early Republic of China, the politics were volatile. In Sichuan province, warlords always stunk in wars and were too busy and too tired to organize the Qingqang Temple Flower Show. As a result, it was organized by Qingyang Temple, Erxian Taoist Temple and nongovernmental economic organization. Whereas, it was noticed that warlords were still maintain order of the Qingqang Temple Flower Show, in order to ensure the normal operation of this activity. Interestingly, it was a wonder of warlords, folk and the temple.

In 1917, after Liu Luo and Liu Dai's two fierce street wars, the Sichuan Ministry of Liu Cunxu expelled Yunnan and Guizhou army out of Sichuan since National Protection War, eventually Sichuan won the temporary peace. In 1918, Xiong Kewu served as military governor of Sichuan, Yang Shukan served as governor of Sichuan province. Since Yang served as this position, he attached great importance to the industry, and released "the Qingyang Temple Flower Show Collection Items Rule " on November 24, 1919 to make all people of the Sichuan province to prepare in the next year.

From Yang's issued wordings, the exposition was still named the Qingyang Temple Flower Show. It was indicated that the authorities have not clearly proposed to changed Flower Show to Industrial Exposition, but just urged all of the industrial bureau conscientiously collecting exhibition products.

By January 1920, The National Bulletin published a piece of news about "Business Association submitted to Provincial Office to request for changing Flower Show to Industrial Exposition". This news also reported the reason of Business Association's request in detail. From their perspective, Qingyang Temple Flower Show named "Trade Union" in the late Qing Dynasty, and at that time "all 
of the local bureau was ordered by authority to collect industrial products and transported to Chengdu to take part in competition, the winners would be awarded and the losers would be impressed", which would "really guide people and it was a good approach to develop industry". On the one hand, the members of the Business Association highly appreciated "Trade Union"in the late Qing Dynasty; on the other hand, they showed dissatisfaction with "Flowers Show" since the Republic of China, the reason for this was that they concerned "how could the two words of Flower Show stand for enough persuasion and reward, as well as revitalization of industry and bring all the spirit of the Lord? In addition, only in terms of this two words, the exposition was not only contain the flowers, so why we must called the exposition as Flowers Show?"

As a result, the members of Business Association proposed the transformation advices, the detail was "renamed Flower Show as Industrial Exposition to promote domestic products and encourage industries by the space of Qingyang Temple like the period of the Late Qing Dynasty."Namely, it returned to the official practice of the New Deal period in the late Qing Dynasty. This report also indicated that the business elites had followed in the footsteps of the elites in the Late Qing Dynasty.

It should be noted that the Industrial Exposition in 1920 had been different with the Late Qing Dynasty, although it also had the meaning of protecting industry and the economy of Sichuan province, it had obviously marked with encouraging the domestic products. There were signs we can also catch a glimpse of official documents. From document of the Government Affairs Office of Sichuan Commission to Security Department of Chengdu in 1921, we can clearly find the reasons of Industry Exposition in 1920, the original text was that "the last year's Industry Exposition was the result of the county Industrial Institute established and their respective missions to collect products and organize the exposition, while promoting domestic products is a matter of the utmost urgency." A Zhuzhi poem had also expressed the meaning of promoting domestic products and carried on a magnificence of swallowing the Eurasian:

"What is the purpose of naming exposition as Industry Exposition? The most important thing is to advocate the domestic products. Some other time we will be rich and strong, please do not forget the favor of the authority. The platform of this exposition is magnificent, the elites' speech and argument are quiet eloquently. The flowers are falling down slice by slice, women and children are ignorant but laugh. More exotic talents gather from everywhere, eyes get dazzled by curios nearly. Industry will be expanded from the exposition, foreign countries can not conquer us."

Actually, looking to the whole country, advocating the domestic products was not the unique movement of Sichuan province, it was the national movement in the 1920s, whereas, Sichuan province was at the forefront of the whole country. Advocating the domestic products means boycott foreign goods and develop the domestic business and industry, in order to push the development of the whole country, and it also means to boycott the foreign invasion through business. In the early period of the Republican of China, enthusiasm of "industrial salvation " became more and more popular, for example, the Ministry of Agriculture and Commerce held Domestic Products Exhibition in Beijing by collected products from provincial Chamber of Commerce. More importantly, influenced by May 4th Patriotic Movement, the enthusiasm of patriotic movement was stronger and stronger, as well as the enthusiasm of advocating the domestic products. In addition, although the working class of Shanghai, who committed to reform the General Chamber of Commerce in Shanghai, were more active than any other places, Chengdu was more advanced than Shanghai, which was ignored by academics. In the spring of 1920, Chengdu reorganized the Industrial Exposition, however, Shanghai held Shanghai General Chamber of Commerce until the end of 1921. Furthermore, Tianjin, which organized Commerce and Industrial Exposition in the same period of Chengdu in the late Qing Dynasty, just established the Tianjin Domestic Product Sale in 1919, then in preparation for the Tangshan Goods Company in 1920. In contrast, the movement of Tianjin was held by folk and businessmen, while, Chengdu's activity was organized by government and was more magnificent. All in all, in the promotion of domestic products in 1920s, Chengdu was listed in forefront of domestic provincial areas.

In addition, another reason for reorganizing Industry Exposition is to advocate autonomy by elites. In 11th years of the Republican of China (1921), the authority held the second Industry Exposition, 
the head of the Government Affairs Office of Sichuan commission- - Xiang Chujin addressed that: "At present it is too hard for Sichuan to hold the Industry Exposition because of financial resources, in other words, the Industry Exposition is just the epitome of Sichuan's industry, at the same time it is also the reflection of the industry spirit in administration. Industry administration is about advocating, maintaining, encouraging and advising industry from provincial governor to local industry superintendent, and it is authoritative. Nowadays it is the period of autonomy, we should carry out authoritative firstly, and then put autonomy into practice. In fact, the authoritative industry is almost passive, while the autonomic industry is automatic......" So the Industry Exposition of Sichuan is also the experimental space of Sichuan local autonomy, namely, Qingyang Temple is just the space which bearing the Industry and autonomy.

The movement of autonomy was raised since the late Qing Dynasty, and it came to a new upsurge in the 1920s. An important reason for the movement of autonomy was to resolve the conflict between central and local power. At the same time, Sun yat-sen also considered that local autonomy was the cornerstone of the Republic of China, only could we realize the local autonomy, we could achieve the development of the Republic of China, then we could achieve national modernization. In the past, scholars focused on the research of Guangdong local autonomy, Hunan local autonomy, or the autonomy thought of Sun yat-sen and Liang Shuming, whereas, Sichuan local autonomy was ignored by scholars. In essence, beyond the effectiveness of Sichuan local autonomy, just considering the rising of it, Sichuan listed in the forefront of the nation. From the authority's point of view, Industrial Expedition was just the experimental site of Sichuan local autonomy to promote the development of local autonomy.

Sichuan reorganized the Industry Exposition in 1920, what was about the any other provinces? Looking around the nationwide, the other provinces did not hold the Industry Exposition, nothing but Agriculture and Commercial Department of, Financial Department the Republic of China discussed about the National Industry Exposition at Temple of Heaven in Beijing in 1921, at that time it was just preparing and did not take any action. Furthermore, the other provinces did not occur any signs of holding the exposition. It was surprised that Fujian province was used to proposed to transformed the space of Industry Exposition to Education Institute, whereas the land had taken back by authority, finally the Education Institute used the backyard of the Examination House. From the national, except Sichuan, any other provinces did not pay enough attention to hold the Industry Exposition, so it was clearly that Sichuan was unique in the nation.

Similarly, it was noted that the Industry Exposition of Sichuan did not caused any concern by other provinces. By combing Shenbao I did not find any reports or comments about the Industry Exposition of Sichuan, although it was the national newspaper. What's more, nowadays the historical scholar have not record anything about the Industry Exposition of Sichuan among the chronicle of the campaign of using the Chinese goods from 1905 to 1952. What is the reason for it? Maybe the reason was just as the professor Wang Dongjie said: "Sichuan was just nearly on the edge of the public voice in China in the 1930s and 1940s." Namely, people besides Sichuan did not take notice of Sichuan's action of advocating domestic goods. While, in fact, Sichuan was tightly followed the step of the campaign of using Chinese goods at that time, even was in the forefront of the whole country.

In conclusion, I want to say that the Industry Exposition of Sichuan was reorganized in 1920 contained complicated reasons, it not only just for promoting industry, but also for encouraging of using the Chinese goods and advocating autonomy. Besides, from the nationwide, Sichuan is unique and in the forefront of the whole country. 


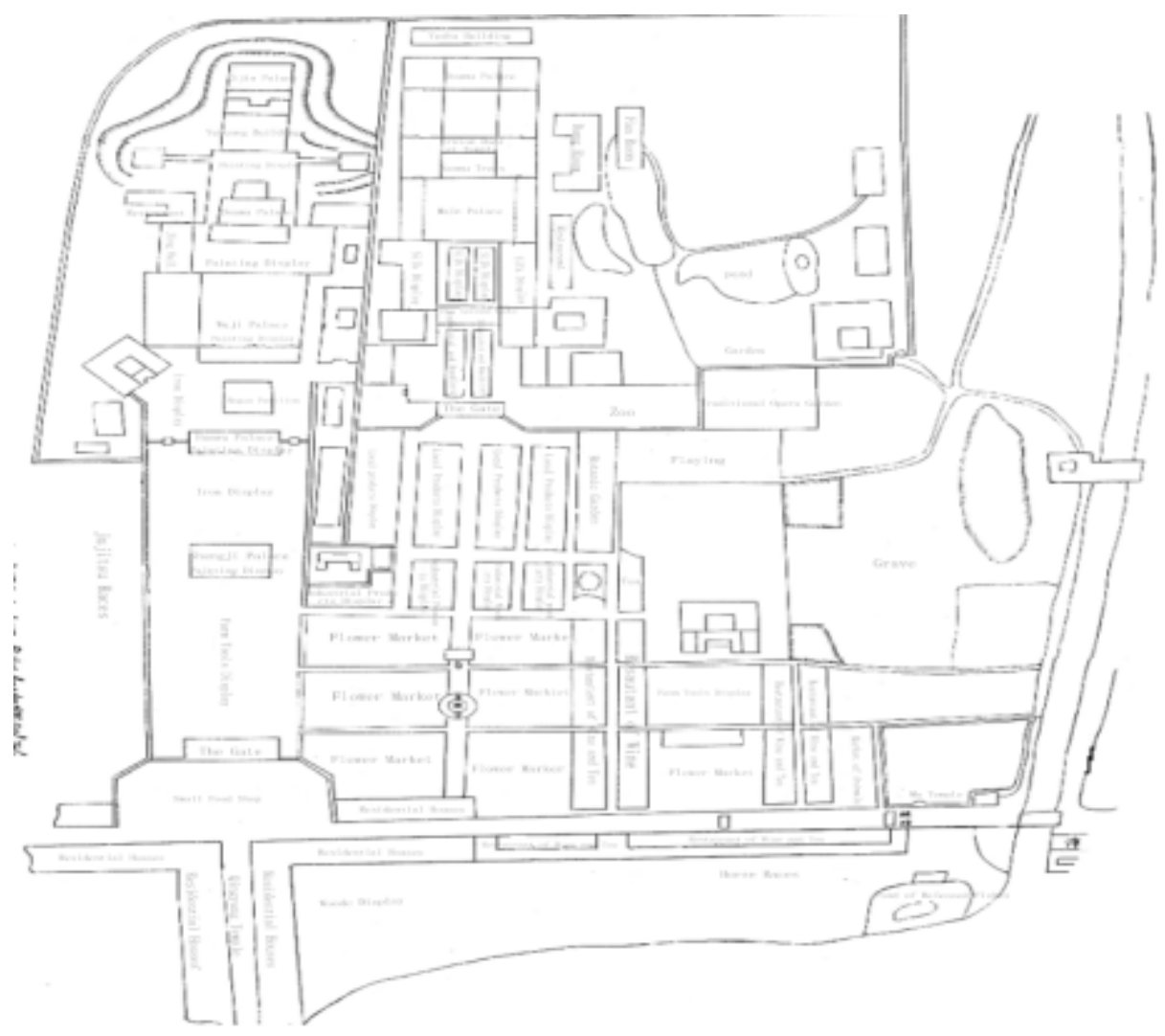

The plane graph of the second Industrial Exposition in 1920

Sources of data: Draw by Preparatory Office of Industrial Exposition in the $10^{\text {th }}$ year of Republican of China in March: Realistic Portrayals - - The plane of Industry Exposition of Chengdu, the Report Book of the Second Industry Exposition of Sichuan Province, 1921.

Above all, we can find that the reasons of Chengdu Qingyang Temple Industrial Exposition was reorganized in the year of 1920 were mainly consisted of two factors. One was financial reason, namely for advocating the domestic products, developing industry and products. The other was about political reason, it was that for advocating autonomy, more importantly, it was means that Industrial Exposition could be a experimental site.

\section{References}

[1] Kuang Shanji, Yang Guangyan editored: The History of Sichuan Warlords, People's Publishing Press of Sichuan, Chengdu, 1991.

[2] Zhou Wenlin, Yang Shukan ordered for 1920 Flower show on Qingyang Temple, Sichuan Archives, vol(1), 2005.

[3] Request for Changing Flower Show to Industrial Exposition, The National Bulletin, January 29th , 1920, Fifth Paper, The Third News.

[4] The Document of the Government Affairs Office of Sichuan Commission to Security Department of Chengdu, the Report Book of the Second Industry Exposition of Sichuan Province, 1921, digital library e-book of CADAL.

[5] Zhu Zhonghui: The poem of the Industry Exposition, The National Bulletin, April 29th ,1920, Seventh Paper, Literature Garden. 
[6] Address • the head of the Government Affairs Office of Sichuan commission's speech, The Reporter of the Second Industry Exposition of Sichuan Province, 1921, digital library e-book of CADAL.

[7] The Launching of the National Industry Exposition, Xinghua, vol(17th), Issue(17th), p28, The Chronicle of Events From Nation to the World.

[8] The 2704th Order of the Head of the Province, Education Administrative Monthly Magazine of Fujian Province, June 25th, 1920, vol(1th), Issue(4th), p15-16, The Order.

[9] Pan Junxiang editored: The Campaign of Using Chinese goods in the Modern China, Beijing: The Press of Culture and History, 1995.

[10] Wang dongjie: The foreign land of China_— The acknowledge of China and Sichuan by the people who had left Sichuan Province in 1930s and 1940s, Historical Study, Issue(3th), 2002. 